\title{
Inclusão Digital: uma realidade sobre a ótica da terceira idade do bairro José e Maria em Petrolina- PE
}

Isaías Coelho, Instituto Federal de Educação Ciência e Tecnologia do Sertão Pernambucano Campus Petrolina, isaiascoelho8@gmail.com

Delza Cristina Guedes Amorim, Instituto Federal de Educação Ciência e Tecnologia do Sertão Pernambucano Campus Petrolina, delzacristina@hotmail.com

Emanuela Vitória Dias Morais, Instituto Federal de Educação Ciência e Tecnologia do Sertão Pernambucano Campus Petrolina, vitoriadm98@gmail.com

Resumo: O presente artigo apresenta os resultados da pesquisa de campo realizada com idosos participantes do curso de inclusão digital na associação das mulheres rendeiras do bairro José e Maria em Petrolina/PE - Brasil. Os resultados foram obtidos através de questionário estruturado e contou com a participação de 9 respondentes. $O$ artigo destaca, inicialmente, a caracterização dos indivíduos, as principais Tecnologias de Informação e Comunicação (TICs) utilizadas, o que eles mais procuram na internet. Além disso, o presente estudo possibilitou identificar as principais dificuldades encontradas na utilização das tecnologias bem como a motivação para participar do curso de inclusão digital.

Palavras-chave: Inclusão digital, TICs, idosos.

\section{Digital Inclusion: a reality from the perspective of the elderly in the José e Maria neighborhood in Petrolina-PE}

\begin{abstract}
This article presents the results of the field research carried out with elderly people participating in the digital inclusion course at the association of women lace makers in the José and Maria neighborhood in Petrolina / PE - Brazil. The results were obtained through a structured questionnaire and counted with the participation of 9 respondents. The article highlights, initially, the characterization of individuals, the main Information and Communication Technologies (ICTs) used, what they most look for on the internet. In addition, the present study made it possible to identify the main difficulties encountered in the use of technologies as well as the motivation to participate in the digital inclusion course.
\end{abstract}

Keywords: Digital inclusion, ICTs, elderly.

\section{Introdução}

No atual contexto social, é preciso pensar na estruturação de uma sociedade justa e que permite que todos os indivíduos a integrem, sem que as diferenças sejam 
motivos de exclusão. Quando se trata de pessoas maiores de 60 anos, o Estatuto do Idoso garante o direito aos mesmos a aprenderem durante a vida "tudo que lhe for útil para aproximar-se do mundo moderno" (Brasil, 2002; Brasil, 2008).

Nos dias atuais, a necessidade de manter-se conectado com TICs atinge todas as camadas populacionais e faixas etárias. Atualmente, as tecnologias estão disseminadas pelo mundo e nas mais diversas atividades. Com o advento da informática, há uma infinidade de informações na rede que precisam de uma organização cognitiva para serem compreendidas. Em se tratando do seu uso, muitas vezes as pessoas, principalmente as de terceira idade, não estão preparadas para compreender a utilização das tecnologias da informação, necessitando de auxílio de outras pessoas para utilizar o aparelho celular, por exemplo (Moro et. al., 2004).

A alfabetização digital se faz necessária para que as pessoas consigam ter acesso e poder utilizar os meios tecnológicos no seu cotidiano como ressalta (Ferreira, 2008, p.45)

É importante dar ênfase a condições que propiciem a inclusão digital, pois a partir do momento em que os idosos passam a ter acesso aos meios informatizados, eles começam a perceber que as tecnologias não são tão complexas como antes imaginavam e que podem aprender e se atualizar, sentindo-se mais valorizados e tornando-se cidadãos.

No entanto, inserir esses indivíduos em curso de inclusão digital é garantir, não somente seus direitos básicos previstos em lei, mas também os tornar mais humano e participativos. Segundo Aguiar (2008), "o uso das novas tecnologias proporciona uma nova visão sobre a escrita, levando a mudanças no pensar e estimulando a busca de conhecimento a respeito disso". É de conhecimento de todos que a população idosa, indivíduos com mais de 60 anos segundo o Estatuto do Idoso e a Organização Mundial de Saúde (OMS), está em constante crescimento (IBGE, 2010), ciclo marcado, basicamente, pelo início da aposentadoria e pelo declínio físico, cognitivo e sensorial.

Ainda, segundo dados divulgados pela OMS, estima-se que em 2025 existirão aproximadamente 1,2 bilhão de pessoas com mais de sessenta anos em todo o mundo. No Brasil, segundo estimativas do Instituto Brasileiro de Geografia e Estatística (IBGE) (2013), a população idosa tende a aumentar exponencialmente, sendo que em 2060 ocorrerá uma inversão na pirâmide da faixa etária populacional. Isso se dá devido ao aumento da expectativa de vida, como é possível observar na figura 1. 

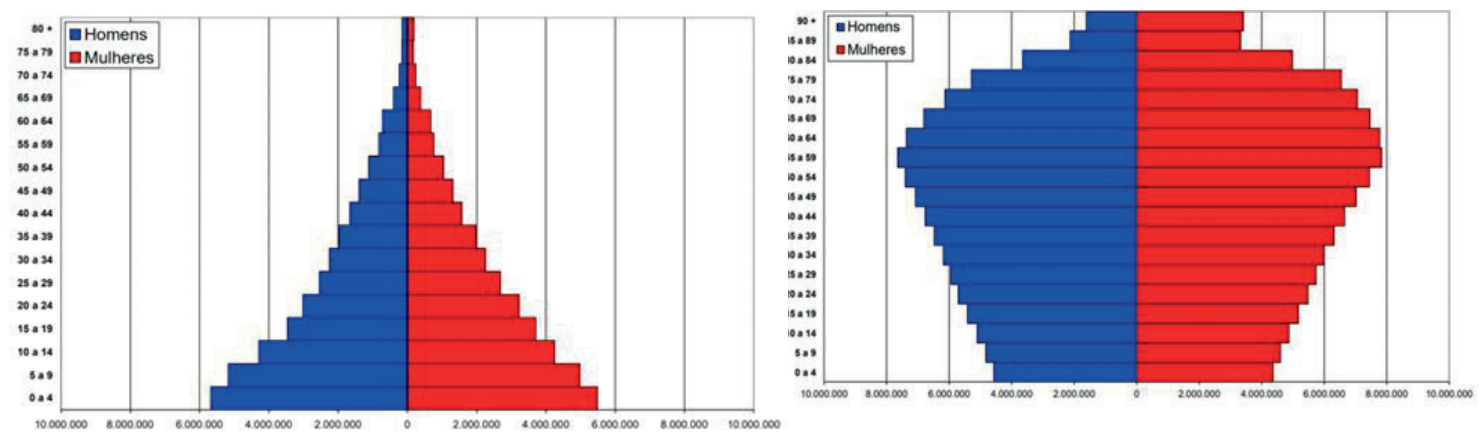

Figura 1 - Gráfico comparativo da evolução do perfil populacional brasileiro de 1960 a 2060

Fonte: IBGE (2013)

Nesta perspectiva de envelhecimento da população, Kachar (2010) ressalta a necessidade de pesquisas sobre a mudança de perfil etário no Brasil para que a sociedade possa se preparar para o envelhecimento, destacando ainda que os estudos devem focar na educação e tecnologia. Nesse sentido podemos perceber que as TICs estão cada vez mais presentes no dia a dia das pessoas, seja na utilização do celular, caixa eletrônico, televisão ou até mesmo no carro, influenciando diretamente na vida dos indivíduos.

Percebe-se que o jovem, nascido na chamada era digital, possui certa facilidade em manusear os equipamentos eletrônicos e se adaptar a estas ferramentas. Por outro lado, os idosos têm dificuldade em compreender as novas tecnologias, visto que estes nasceram em uma época totalmente diferente da realidade atual, e necessitam de uma abordagem adequada para inclui-los no universo da informática.

Nesse cenário, vale ressaltar que o processo de inclusão digital na terceira idade traz múltiplos benefícios para esse público, pois possibilita uma melhora nas condições psicológicas e de interação, conforme firma Jantsch (2012, p. 173):

Atualmente as TIC (Tecnologias de Informação e Comunicação), têm contribuído para a difusão do conhecimento por diversos meios, utilizando para isso ferramentas digitais. Estas ferramentas permitem não só a pesquisa, mas também oferecem condições para que o conhecimento seja partilhado e socializado. Assim, estas tecnologias podem ajudar as pessoas idosas a diminuir o isolamento e a solidão, aumentando as possibilidades de manter contato com familiares e amigos, incluindo suas relações sociais através da utilização das redes sociais digitais como uma ferramenta facilitadora para a concretização do envelhecimento ativo.

Para indivíduos de idade mais avançada, as tecnologias vieram como uma oportunidade de inserção no meio social. Entretanto, é preciso que essa ferramenta seja utilizada para proporcionar uma melhor qualidade de vida, inibindo o isolamento muito comum desses indivíduos. Muitos idosos têm apresentado dificuldades na utilização das novas tecnologias, pois existe um ritmo próprio, que diverge de como jovens compreendem as informações que lhe são passadas. Nesse sentido, Arens e Moraes (2014, p. 01) destacam que 
[...] A geração de idosos de hoje tem revelado suas dificuldades em entender a nova linguagem e em lidar com os avanços tecnológicos até mesmo nas questões mais básicas como os eletrodomésticos, celulares, caixas eletrônicos instalados nos bancos. Consequentemente, aumenta o número de idosos iletrados em Informática, ou analfabetos digitais, em todas as áreas da sociedade.

Num momento onde a contribuição das tecnologias tem favorecido todos os ramos da sociedade, desde as compras, operações bancárias além de atividades diárias básicas, elas se tornaram imprescindíveis nas mais diversas atividades. Entretanto, o processo de restrição de uso também cresce de forma conjunta, diante da existência dos analfabetos digitais, aqueles indivíduos que apresentam desconhecimento acerca do uso desses novos métodos tecnológicos (Pires, 2013).

Diante disso, o respectivo estudo teve por objetivo geral analisar o uso das TICs no dia a dia das pessoas, sob a ótica da terceira idade, com alunos participantes do curso de Inclusão digital realizado na associação das mulheres rendeiras no bairro José e Maria em Petrolina - PE. Assim, a pesquisa partiu das seguintes questões: Q1) Quais as TICs que esse grupo de idosos utiliza? Q2) Quais as motivações para participar do curso de inclusão digital? Q3) Quais principais dificuldades que os idosos encontram com o uso das TIcs? Q4) O que os idosos mais procuram na internet?

\section{Referencial Teórico}

O envelhecimento da população associado com o aumento da expectativa de vida tem se tornado uma preocupação para a humanidade, de modo que é preciso que sejam estruturadas políticas de assistência a esses indivíduos, garantindo qualidade de vida e acima de tudo, inserindo-o na sociedade, para que ele possa manter-se ativo (Goulart, 2007). É muito importante que eles tenham acesso a atividades diversas, desde bailes, confraternizações e outras formas de participação, em que possam desenvolver ou estimular habilidades (Harada, 2011).

Em função de essa população estar se apresentando de forma significativa na sociedade, muitas das propostas do "mercado" têm sido direcionadas a eles. Não obstante, em relação as novas tecnologias têm se dado no mesmo sentido, e inclusão dos idosos na era digital tem sido vista como um dos objetivos mais relevantes (Jantsch, 2012).

A inclusão é vista nos dias atuais como uma inovação, cujo sentido tem sido muito distorcido e polêmico. É um movimento de luta das pessoas de todas as ordens e seus familiares na busca dos seus direitos e lugar na sociedade. No entanto, inserir essas pessoas nada mais é do que garantir não somente seus direitos básicos previstos em Lei, mas também os tornar mais humanos e participativos.

Segundo Aguiar (2008), o uso das novas tecnologias proporciona uma nova visão sobre a escrita, levando a mudanças no pensar e estimulando a busca de conhecimento a respeito disso. Isso é um fator fundamental, influenciando de forma direta ou indireta os conteúdos e atividades educativas.

Além disso, é sabido que o processo de envelhecimento ocasiona em diversas mudanças na rotina dos indivíduos, em função de suas limitações físicas e mentais. $\mathrm{O}$ 
idoso tende a realizar associações no processo de aprendizagem, levando com consideração experiências anteriores.

Ao iniciar o uso do computador como um recurso terapêutico, por exemplo, o idoso passa por todo um processo de aprendizagem, o qual possibilitará o aprimoramento de suas habilidades motoras, comunicativas e sociais (SÉ, 2014).

Esse processo de aprendizagem é fundamental na questão da inclusão tecnológica do idoso, porque proporciona que o mesmo seja inserido dentro do ambiente social moderno, deixando de ser um indivíduo à margem do mundo moderno (CASTELLS, 2003).

\section{Metodologia}

O processo de coleta de dados deste trabalho consiste em um levantamento bibliográfico que serviu como base para a fundamentação teórica do assunto abordado, integrando uma pesquisa exploratória descritiva de classificação qualitativa, com abordagem exploratória descritiva delineada pela pesquisa de campo, com aplicação de questionário. De acordo com Gil (1999), as pesquisas descritivas têm como finalidade principal a descrição das características de determinada população ou fenômeno, ou o estabelecimento de relações entre variáveis e sua relação com o objeto de estudo. Com relação a sua classificação como pesquisa exploratória, Malhotra et al (2005) nos diz que ela tem como principal objetivo proporcionar esclarecimento e compreensão para o problema enfrentado.

Para realização deste trabalho foi aplicado um questionário estruturado composto por 16 perguntas abertas e fechadas, abordando temas como gênero, idade, escolaridade, uso dos computadores, acesso à internet. Participaram da pesquisa 9 pessoas com idade igual ou superior a 60 anos, participantes do curso de inclusão digital ofertado no âmbito do Programa Institucional de Bolsas de Extensão (Pibex) do Instituto Federal de Educação Ciência e Tecnologia do Sertão Pernambucano, Campus Petrolina. O curso ocorreu na associação das mulheres rendeiras do bairro José e Maria na cidade de Petrolina/PE.

\section{Resultados e discussão}

Com o propósito de atingir os objetivos elencados inicialmente neste trabalho, cujo objetivo geral consiste em analisar o uso da TICs no dia a dia das pessoas sob a ótica da terceira idade dos alunos participantes do curso de Inclusão digital realizado na associação das mulheres rendeiras no bairro José e Maria em Petrolina/PE, foi aplicado um questionário que contou com a participação de nove (09) idosos participantes do curso citado anteriormente. O roteiro do questionário contemplou a caracterização dos idosos e questões relativas ao uso das tecnologias de informação e comunicação por esse público no seu cotidiano.

Ao analisar o perfil dessa população quanto ao gênero, observou que a maioria dos idosos que fazem parte do curso em questão são representantes do sexo feminino $(\mathrm{n}=7 ; 77,8 \%)$. Esse fato pode ser explicado, conforme Garcia (2001), porque muitos idosos, em especial os homens, possuem certa resistência em aprender e usar informática e o público feminino está buscando cada vez mais o aprimoramento nas 
mais diversas áreas, principalmente no uso das tecnologias, participando de cursos de inclusão digital. Ainda nesse contexto, Cardoso et al. (2014) declara que os idosos do sexo feminino demonstram maior interesse em participar de novas experiências, deixando de lado o preconceito e quebrando paradigmas a exemplo de que os idosos não são capazes de aprender.

Em relação à faixa etária dos respondentes, foi possível verificar que 55,6\% $(\mathrm{n}=5)$ possuem entre 60 a 65 anos de idade; 22,2\% $(\mathrm{n}=2)$ estão na faixa etária de 70 anos e $22,2 \%(n=2)$ informaram ter idade entre 76 a 80 anos. Desse modo, todos os indivíduos que participaram desta pesquisa se enquadram no grupo da terceira idade, uma vez que de acordo com o Estatuto do Idoso, a população da terceira idade está relacionada às pessoas com idade igual ou superior a 60 (sessenta) anos de idade.

No que diz respeito ao grau de escolaridade dos idosos informantes, foi possível verificar que a maioria dos respondentes $(n=4 ; 44,4 \%)$ possui ensino médio completo, $22,2 \%(\mathrm{n}=2)$ têm ensino fundamental incompleto e $11,1 / \% \quad(\mathrm{n}=1)$ têm ensino fundamental completo, $11,1 \%(n=1)$ ensino superior completo $11,1 \%(n=1)$ tem ensino médio incompleto. Esses dados da pesquisa condizem com o estudo de Carvalho, Arantes e Cintra (2016) sobre a inserção de idosos na era digital onde não existiram idosos considerados analfabetos, todos os participantes da pesquisa sabiam ler e escrever. Isso demonstra que não se pode afirmar que a dificuldade para compreensão do uso das TICs seja intelectual, podendo estar relacionada com o fato de nunca ter sido apresentado a esse indivíduo tais novidades.

Com o objetivo de identificar como está se dando o processo de inclusão digital, foi questionado aos idosos participantes já tinha feito algum curso na área de informática, identificou-se que 55,6\% $(n=5)$ dos idosos afirmaram que já participaram de algum curso de informática, enquanto $44,4 \%(n=4)$ ainda não o fizeram. Da mesma forma, a maior parte deles $(\mathrm{n}=8 ; 88,9 \%)$ indicou possuir computadores em casa, e apenas $11,1 \%(\mathrm{n}=1)$ disseram não possuir o equipamento.

No questionário aplicado aos idosos, foi lhes apresentado algumas questões onde as respostas poderiam ter variação entre nunca, raramente, às vezes, frequentemente e sempre. Ao serem questionados sobre a influência que as tecnologias têm na tomada de decisões, observou-se que as respostas oscilaram, em sua maioria, entre frequentemente e às vezes, o que indica que eles percebem a importância das TICs no cotidiano. Além disso, as informações que são adquiridas na internet estão influenciando também na tomada de decisões desses indivíduos, demonstrando quão importante é integrá-los nessa nova cultura.

A respeito dos benefícios que a utilização dos computadores proporciona para o idoso, $88,9 \%(n=8)$ dos respondentes julgaram que sempre tem benefícios e apenas $11,1 \%(\mathrm{n}=1)$ indicaram a resposta frequentemente. Observa-se que a utilização dos computadores pode ser uma excelente atividade de estímulo mental, auxiliando na manutenção da memória e proporcionando o aprendizado constante. Dentre os equipamentos eletrônicos mais utilizados que foram citados pelos participantes destacam- se o celular, computador e o caixa eletrônico.

A respeito da utilização da internet pelos idoso $77,8 \%(n=7)$ afirmaram que sempre estão conectados à internet no seu dia a dia, e apenas $22,2 \%(n=2)$ faz uso apenas em algumas ocasiões. No quesito dificuldades de acessar internet, a maior parte dos respondentes $(n=7 ; 77,8 \%)$ afirmaram que às vezes tem dificuldades de acessar. Essa informação vai ao encontro com o que diz Franco (2013) sobre os nativos digitais, que são indivíduos que não só nasceram em um mundo cercado por tecnologia digital, mas que também fazem uso de meios digitais como parte integrante de suas vidas. 
Avaliando o grau de importância do uso dos computadores da internet 88,9\% $(\mathrm{n}=8)$ afirmaram que é sempre importante saber dominar essas ferramentas. Essa informação pode ser fortalecida pelo fato de que, com a expectativa de vida elevada, a participação dos indivíduos no mercado de trabalho também tem se intensificada, exigindo domínio no uso dos meios eletrônicos (Pires, 2013).

A respeito do curso de inclusão digital oferecido, $66,7 \%(n=6)$ dos participantes afirmaram que sua participação no curso facilitou sua aprendizagem quanto ao uso das tecnologias, e isso é muito importante nas atividades do cotidiano. Esse fato chama a atenção para a relevância que essas atividades de inclusão digital têm na vida desses idosos, tornando-os mais ativos e dispostos a aprender.

Nos tópicos a seguir os idosos responderam perguntas dissertativas. Com o intuito de preservar a privacidade da identidade dos respondentes, seus nomes foram alterados e abreviados para suas iniciais.

\section{Questão sobre o que os idosos mais procuram na internet}

A maioria dos idosos relatou o que mais procura na internet, dentre eles destacamos a busca por "artesanatos em couros" (N. M. S. A). e buscar informações, conversar com familiares através de aplicativos de mensagens, "Conversar com os familiares" (F. E.S); "Buscar notícias e conversar com familiares" ( M. J. C. G); "Ficar atualizado com os acontecimentos do Brasil e do mundo" (J.D.S) e "Pesquisa, ultimamente para entrar nas reuniões, lives" (G.C.C.S).

Nesse sentido, Kachar (2001), ressalta que as TICs contribuem no processo de redução do isolamento dos idosos, bem como na estimulação mental e na redução do sentimento de inutilidade nesses indivíduos. Desse modo, favorece o seu bem-estar e facilitando o estreitamento dos laços afetivos estabelecidos mediante a aproximação com os parentes e amigos através da internet

\section{Questão sobre as dificuldades e facilidades encontradas pelos idosos no uso do computador e/ou outros equipamentos eletrônicos}

Dentre as principais dificuldades e facilidades encontradas pelos idosos indicadas no questionário, destacam-se o fato de não saber utilizar o teclados e não entenderem os programas de computadores: "Quanto mais a gente usa mais fácil vai ficando, e as dificuldades vão diminuindo"(J.D.S); "Dificuldade em usar determinados sistemas, facilidade de entender mensagens, leituras" (M.D.S); "Acessibilidade"(C.J.R); "Dificuldades de entender as siglas e as facilidades de buscar coisas novas"(A.M.S); "Minha dificuldade ao pesquisar é quando aparece vários títulos, fico sem saber qual o correto, medo de acessar, baixar alguns aplicativos, quando tem que preencher algum formulário, às vezes tenho dúvidas, edital de concurso"(G.C.C.S); "Não saber o usar os botões adequadamente. Ficar bem informadas sobre atualidades", (N.M.S.A); "Não sei procurar as coisas na internet" (F.E. S); "Dificuldade de entender os programas" (M. J. C. G) e "Entender os sistemas do computador" (E. C. A).

\section{Motivações dos idosos para participar do curso de Inclusão Digital}


$\mathrm{Na}$ percepção dos idosos participantes respondentes, a possibilidade de aprender coisas novas e ter acesso à informação "teve origem na vontade de buscar mais conhecimento sobre o mundo atual na era da tecnologia" (G.C.C.S); "Conhecer melhor o meus país, ficar bem informado dos acontecimentos do Brasil e do mundo". (J.D.S); "Aprender mais" (M.D.S); "Aprender usar todos meios de comunicação" (C.J.R); "Foi justamente para sanar as dúvidas que tinha" (A.M.S); "Aprender todas informações necessárias a fim de saber entrar em qualquer assunto da Internet com segurança!" (N.M.S.A); "Se aperfeiçoar e aprender trabalhar com a internet" (F.E. S); "Aprender a utilizar os computadores" (M. J. C. G) e "Motivaria aprender a usar mais coisas" (E. C. A).

Para Goulart (2007), quando um idoso fica motivado a aprender ou reaprender e quer se apropriar das tecnologias de informação, através da inclusão digital, sabendo usá-las a seu favor, torna a aprendizagem mais prazerosa.

\section{Considerações finais}

Os resultados do presente estudo indicam que a expectativa de vida no Brasil tem se elevado a cada ano, e consequentemente, a participação dos indivíduos acima de 60 anos de idade nas mais diversas atividades da sociedade cresceu de forma conjunta com esse parâmetro. Nesse contexto, ressalta-se a relevância da inclusão digital em tempos altamente tecnológicos, onde as ações globalizadas tomaram proporções gigantescas.

Outro aspecto interessante observado na pesquisa é que a maioria dos idosos utilizam a internet para se comunicar com familiares, realizar pesquisas sobre assuntos da atualidade e se manterem informados. Entre as dificuldades encontradas por esse grupo ao utilizarem o computador, eles mencionam não saber utilizar corretamente o teclado e não entenderem os programas. Essas dificuldades são muito comuns em pessoas de idade mais avançada, diferentemente do que em jovens, que já nascem conectados. Sendo assim, é notório que o processo de inclusão digital facilita o processo de aprendizagem uma vez que as tecnologias estão em constante avanço.

Desse modo, em função de muitos idosos já conviverem com os meios tecnológicos, e muitas vezes residirem longe de seus familiares, os mecanismos digitais representam uma potencial ferramenta de inclusão desses indivíduos. Vale ressaltar que as dificuldades citadas no uso desses meios não se relacionam com déficit intelectual, e sim com falta de prática, contrariando o pensamento comum a cerca desse grupo etário.

\section{Referências}

AGUIAR, E.V.B. As novas tecnologias e o ensino-aprendizagem. Vértices. V.10, n.1/3. Jan/dez. 2008. P.63-71.

ARENS, Alexandre; MORAES, Márcia Cristina. Inclusão Digital na Terceira Idade: um relato de experiência realizado no Sinttel/RS.Rio Grande do Sul, 2014. Disponívelem:http://docplayer.com.br/8997662-Inclusao-digital-na-terceira-idade-um-r elato-de-experiencia-realizado-no-sinttel-rs.htm 1 Acesso em 02 de outubro de 2020. 
AGUIAR, E.V.B. As novas tecnologias e o ensino-aprendizagem. Vértices. V.10, n.1/3. Jan/dez. 2008. P.63-71

BRASIL. Projeto de Lei da Câmara dos Deputados n. 4099/2012. Altera o art. 1.788 da Lei n. ${ }^{\circ}$ 10.406, de 10 de janeiro de 2002, que "institui o Código Civil". Disponível em:

http://www.camara.gov.br/proposicoesWeb/fichadetramitacao?idProposicao $=548678$. Acesso em: Acesso em 02 de outubro de 2020.

BRASIL. Ministério do planejamento, orçamento e gestão. Instituto Brasileiro de Geografia e estatística - IBGE . Projeção da população do Brasil por sexo e idade 1980-2050. Rio de Janeiro: IBGE, n. 24, 2008. 93p.

CARDOSO, R. G. S et al. Os benefícios da informática na vida do idoso. Computer on the Beach. p. 1-10. Disponível em: https://siaiap32.univali.br/seer/index.php/acotb/article/view/5338/2795. Acesso em 27 de outubro de 2020.

CARVALHO, Eliana; ARANTES, Rodrigo Caetano; CINTRA, Angélica Sartori Rossi. A inserção de idosos do Instituto Henrique da Silva Semente (IHESS) no município de Indaiatuba/SP na era digital: contribuições fisiogerontológicas. Rev. bras. geriatr. gerontol., Rio de Janeiro , v. 19, n. 4, p. 567-575, Aug. 2016 . Disponível em: http://www.scielo.br/scielo.php?script=sci_arttext\&pid=S1809-98232016000400567\&1 $\mathrm{ng}=\mathrm{en} \& \mathrm{nrm}=\mathrm{iso}$. Acesso em 27 de outubro de 2020.

CASTELLS, Manuel. A Galáxia da Internet: reflexões sobre a internet, os negócios e a sociedade. Rio de Janeiro: Jorge Zahar Editor, 2003.

FERREIRA, Anderson Jackle. Terceira Idade: novas tecnologias e solidariedade. In: TERRA, Newton Luiz. DORNELLES, Beatriz. (orgs.). Envelhecimento bem sucedido. 2. ed. Porto Alegre. EDIPUCRS. 2008.

FRANCO, Claudio de Paiva. Compreender as experiências de aprendizagem dos nativos digitais. Rev. bras. linguista. apl., Belo Horizonte, v. 13, n. 2, pág. 643-658, junho de 2013. Disponível $\mathrm{em}$ http://www.scielo.br/scielo.php?script=sci_arttext\&pid=S1984-63982013000200013\&1 ng=en\&nrm=iso. Acesso em 27 de outubro de 2020.

GARCIA, H. D. A Terceira Idade e a Internet: uma questão para o novo milênio. Dissertação (Mestrado em Ciência da Informação), Universidade Estadual Paulista, Campus Marília, Marília, São Paulo. 2001.

GIL, A. C. Métodos e técnicas de pesquisa social. 5.ed. São Paulo: Atlas, 1999.

GOURLART, D. Inclusão digital na terceira idade: a virtualidade com objeto e reencantamento da aprendizagem. Dissertação (Mestrado). Programa de Pós Graduação em Educação, PUC - RS, Porto Alegre. 2007. Disponível em: http://repositorio.pucrs.br/dspace/handle/10923/2850. Acesso em 27 de outubro de 2020. 
HARADA, Ruth. Tecnologia e Inclusão Social. 2011. Disponível em: http://www.ideiasustentavel.com.br/2011/02/tecnologia-aponta-caminhos-para-engajam ento-e-inclusao-social/. Acesso em 27 de outubro de 2020.

INSTITUTO BRASILEIRO DE GEOGRAFIA E ESTATÍSITICA (IBGE). Informações importantes sobre envelhecimento. 2013. Disponível em: http://www.ibge.gov.br/home/estatistica/populacao/projecao_da_populacao/2008/projec Acesso em 27 de outubro de 2020.

. Sinopse do Censo Demográfico 2010. Disponível em: http://biblioteca.ibge.gov.br/visualizacao/livros/liv49230.pdf. Acesso em 27 de outubro de 2020 .

JANTSCH, Anelise. et al. As Redes Sociais e a Qualidade de Vida: Os Idosos na Era Digital. Rio Grande do Sul, Nov. 2012. vol. 7, Núm. 4. Disponível em http://rita.det.uvigo.es/201211/uploads/IEEERITA.2012.V7.N4.A2.pdf Acesso em 03 de outubro de 2020.

KACHAR, V. A terceira idade e o computador: interação e produção num ambiente educacional interdisciplinar. Tese de Doutorado em Educação. São Paulo, PUC. 2006.

KACHAR, V. Terceira Idade \& Informática: Aprender revelando potencialidades. São Paulo: Cortez; 2003.

MALHOTRA et al,. Introdução a Pesquisa de Marketing. São Paulo: Pearson Prentice Hall, 2005.

MORO, E. et al. As novas tecnologias da informação e comunicação e a pesquisa escolar. Porto Alegre: [s. n.], 2004.

PIRES, L. L. D. A. Envelhecimento, tecnologias e juventude: caminhos percorridos por alunos de cursos de informática e seus avós. Estudos interdisciplinares sobre o envelhecimento, 18(2), 293-309. Disponível em: http://seer.ufrgs.br/index.php/RevEnvelhecer/article/view/34181/27659 Acesso em 02 de outubro de 2020 .

SÉ. Elisandra Vilella G. Mente na Terceira Idade. s/d. Disponível em: http://gazetaweb.globo.com/portal/noticia-old.php?c=202988\&e=19. Acesso em 28 de outubro de 2020. 